\title{
Konsentrasi Karbon Monoksida (CO) di Kota Pontianak
}

Riski Andriania, Nurhasanaha, Riza Adriat ${ }^{\mathrm{b} *}$

aProdi Fisika, FMIPA Universitas Tanjungpura, bProdi Geofisika, FMIPA Universitas Tanjungpura

*Email : rizaadriat@physics.untan.ac.id

\begin{abstract}
Abstrak
Penelitian ini bertujuan untuk menentukan nilai konsentrasi gas karbon monoksida (CO) dan mengetahui pengaruh suhu udara terhadap konsentrasi gas CO di Jalan Gajah Mada dan Jalan Tanjungpura Kota Pontianak. Pengukuran konsentrasi CO dilakukan setiap 1 jam pada pukul 06.00 - 22.00 WIB selama 6 hari di 6 titik, yaitu 3 titik di Jalan Gajah Mada dan 3 titik di Jalan Tanjungpura. Hasil penelitian menunjukkan kadar gas CO di Jalan Gajah Mada berkisar antara 2.746,69-11.215,66 $\mu \mathrm{g} / \mathrm{Nm}^{3}$ dan Jalan Tanjungpura berkisar 2.060,02-15.564,58 $\mu \mathrm{g} / \mathrm{Nm}^{3}$. Nilai tersebut masih berada di bawah baku mutu udara ambien dari PERMENLH No. 12 tahun 2010, yaitu $30.000 \mu \mathrm{g} / \mathrm{Nm}^{3}$. Pada pengukuran pagi, siang, dan sore hari konsentrasi gas CO cenderung berbanding terbalik dengan suhu udara, namun menjadi cenderung berbanding lurus pada malam hari.
\end{abstract}

Kata Kunci : Karbon Monoksida (CO), Suhu Udara

\section{Latar Belakang}

Karbon monoksida (CO) merupakan gas beracun yang terbentuk akibat adanya proses pembakaran yang tidak sempurna dalam proses kerja motor yaitu berupa gas buangan [1]. Gas CO yang terhirup oleh manusia akan masuk ke dalam saluran pernafasan dan kemudian berikatan dengan hemoglobin darah membentuk carboxy hemoglobin (COHB). Semakin tinggi konsentrasi gas CO yang terhirup oleh manusia maka semakin fatal resiko yang diterima oleh manusia tersebut, bahkan dapat menyebabkan kematian [2].

Penyebaran gas CO di udara tergantung pada keadaan lingkungan. Daerah perkotaan dengan tingkat lalu lintas yang padat akan menghasilkan kadar gas CO yang relatif tinggi [1]. Unsur cuaca seperti intensitas penyinaran matahari, angin, suhu udara, dan kelembapan udara merupakan media perantara dalam proses penyebaran polutan [3].

Sebelumnya telah dilakukan kajian konsentrasi gas CO di Kota Semarang yang memperlihatkan adanya peningkatan gas CO dengan bertambahnya jumlah kendaraan bermotor dan adanya unsur cuaca (suhu udara, kelembapan udara, dan kecepatan angin). Gas CO cenderung berkurang seiring dengan meningkatnya suhu udara [4][5]. Pengaruh jumlah kendaraan bermotor terhadap konsentrasi gas CO mencapai 0,808 dan pengaruh unsur cuaca masing-masing yaitu 0,461; 0,239; dan -0,741 [6].

Jalan Gajah Mada dan Jalan Tanjungpura merupakan kawasan peruntukkan perdagangan dan jasa di Kota Pontianak, sehingga jalan tersebut sering dilalui oleh kendaraan bermotor.
Kondisi tersebut dapat mempengaruhi tingkat konsentrasi gas CO. Keberadaan bangunanbangunan yang relatif tinggi di kedua sisi jalan memungkinkan adanya penumpukan gas CO di daerah tersebut. Selain kendaraan bermotor, suhu udara yang selalu berubah terhadap waktu juga menjadi salah satu faktor yang mempengaruhi gas CO di udara. Pada penelitian ini dilakukan pengukuran konsentrasi gas CO dengan memperhatikan pengaruh suhu udara terhadap konsentrasi gas CO di Jalan Gajah Mada dan Jalan Tanjungpura Kota Pontianak.

\section{Metodologi}

\subsection{Waktu dan Tempat Penelitian}

Pengambilan data dilakukan pada hari kerja, yaitu tanggal 6, 7, 8, 9, 13, dan 14 Agustus 2018. Lokasi penelitian yaitu di Jalan Gajah Mada dan Jalan Tanjungpura Kota Pontianak. Titik pengukuran G I, G II, dan G III berada di Jalan Gajah Mada sedangkan T I, T II, dan T III di Jalan Tanjungpura (Gambar 1).

\subsection{Alat dan Bahan}

Alat dan bahan yang digunakan pada penelitian yaitu CO meter Lutron GCO-2008, global positioning system (GPS) Garmin dengan jenis GPSmap 64s, dan stopwatch.

\subsection{Data Penelitian}

Pengambilan data konsentrasi gas CO dan suhu udara dilakukan menggunakan CO meter. Penentuan titik koordinat lokasi pengamatan dilakukan menggunakan GPS. Proses pengukuran dilakukan setiap 1 jam dari pukul 06.00 - 22.00 WIB, kemudian data yang muncul pada alat setiap 5 menit dicatat. 


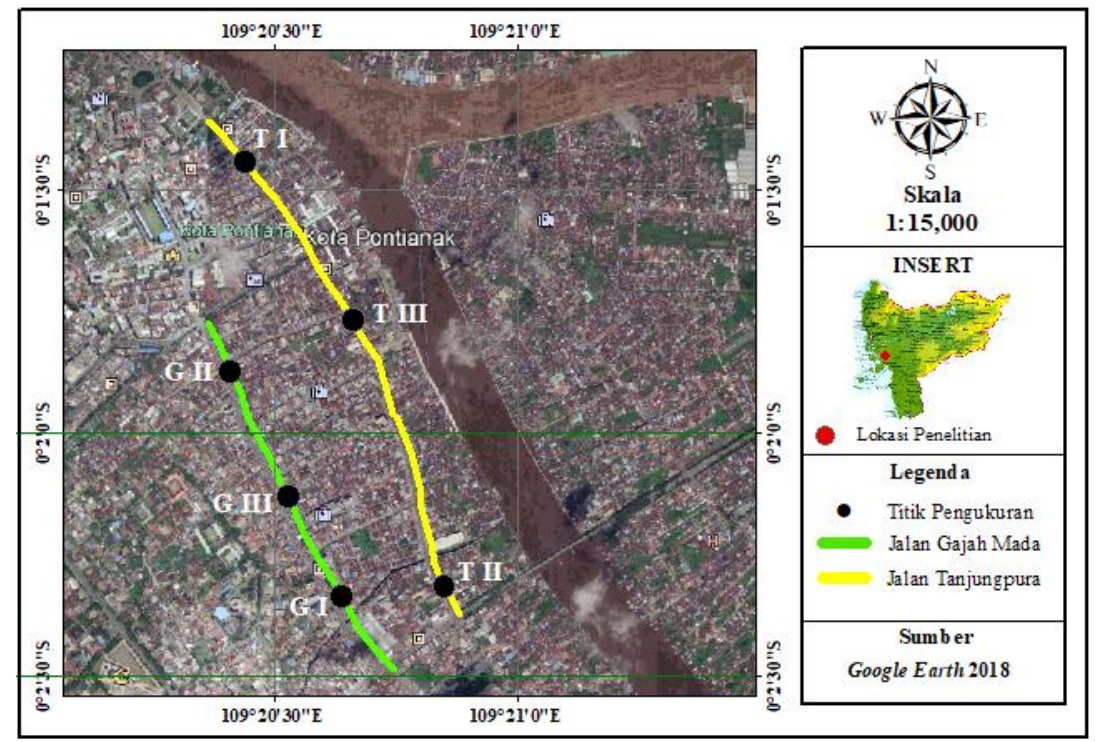

Gambar 1. Lokasi penelitian dan titik pengukuran

\subsection{Pengolahan dan Analisis Data}

Data konsentrasi gas CO dan suhu udara diplot dalam grafik untuk melihat kondisi tempat pengukuran. Analisa dilakukan dengan melihat sebaran gas CO dan pengaruh suhu udara terhadap konsentrasi gas CO. Hasil pengukuran gas $\mathrm{CO}$ tersebut dibandingkan dengan baku mutu udara ambien (BMUA) dari PERMENLH No. 12 tahun 2010 untuk mengetahui kualitas udara di tempat pengukuran [7].

\subsection{Diagram Alir}

Alur penelitian dapat dilihat pada Gambar 2.

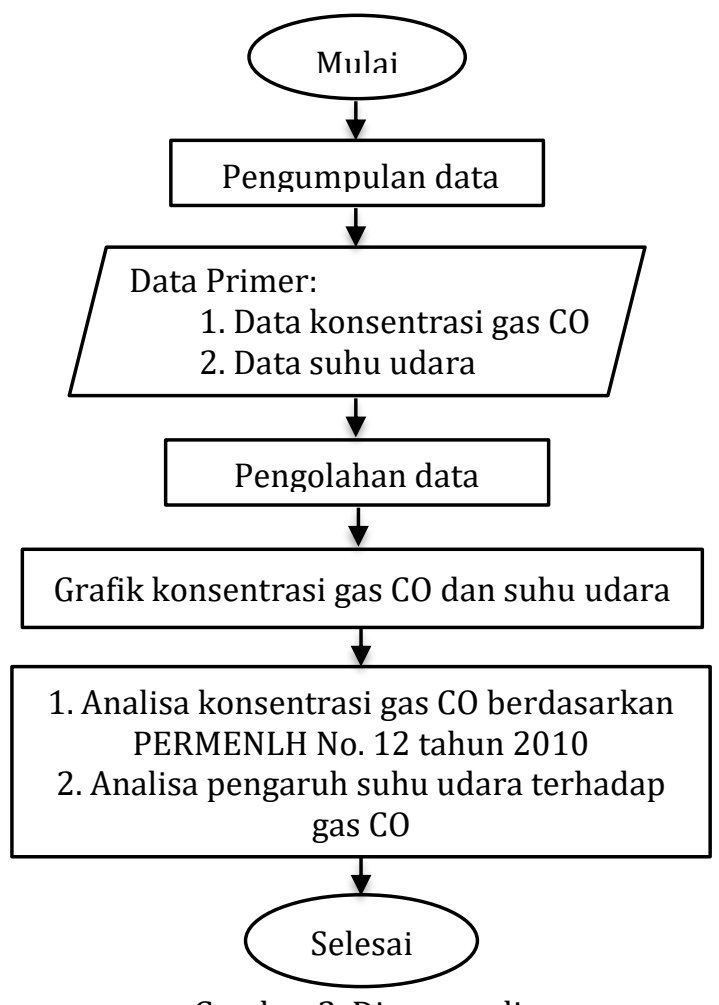

Gambar 2. Diagram alir

\section{Hasil dan Pembahasan}

3.1 Konsentrasi Gas Karbon Monoksida (CO) Gambar 3(a) menunjukkan konsentrasi gas CO di Jalan Gajah Mada. Konsentrasi gas CO ratarata pada pagi hari pukul 06.00 - 07.00 WIB sebesar 8.468,97 $\mu \mathrm{g} / \mathrm{Nm}^{3}$. Rata-rata konsentrasi gas CO pada siang hari pukul $12.00-13.00 \mathrm{WIB}$ yaitu $3.967,44 \mu \mathrm{g} / \mathrm{Nm}^{3}$. Hasil pengukuran pada sore hari pukul 14.00 - $17.00 \mathrm{WIB}$, rata-rata konsentrasi gas $\mathrm{CO}$ cenderung meningkat sebesar $6.052,89 \mu \mathrm{g} / \mathrm{Nm}^{3}$. Konsentrasi gas $\mathrm{CO}$ rata-rata pada malam hari pukul $21.00-22.00$ WIB cenderung turun hingga $3.166,33 \mu \mathrm{g} / \mathrm{Nm}^{3}$.

Gambar 3(b) menunjukkan konsentrasi gas CO di Jalan Tanjungpura. Konsentrasi gas CO rata-rata pada pagi hari pukul $06.00-07.00 \mathrm{WIB}$ sebesar 9.537,12 $\mu \mathrm{g} / \mathrm{Nm}^{3}$. Rata-rata konsentrasi gas CO pada siang hari pukul $11.00-12.00$ WIB cenderung menurun menjadi $3.853 \mu \mathrm{g} / \mathrm{Nm}^{3}$. Hasil pengukuran pada sore hari pukul 15.00 16.00 WIB, rata-rata konsentrasi gas CO cenderung meningkat lagi sebesar 7.095,62 $\mu \mathrm{g} / \mathrm{Nm}^{3}$. Konsentrasi gas CO rata-rata pada malam hari pukul $21.00-22.00$ WIB cenderung turun kembali hingga $2.861,14 \mu \mathrm{g} / \mathrm{Nm}^{3}$.

Konsentrasi gas CO yang diperoleh di jalan Gajah Mada berkisar antara 2.746,69-11.215,66 $\mu \mathrm{g} / \mathrm{Nm}^{3}$ dan di Jalan Tanjungpura berkisar $2.060,02-15.564,58 \mu \mathrm{g} / \mathrm{Nm}^{3}$. Jika dibandingkan dengan baku mutu udara ambien (BMUA) dari PERMENLH No. 12 tahun 2010, nilai konsentrasi gas $\mathrm{CO}$ yang diperoleh baik di Jalan Gajah Mada (titik G I, titik G II, titik G III) maupun di Jalan Tanjungpura (titik T I, titik T II, titik T III) masih berada di bawah ambang batas BMUA yaitu $30.000 \mu \mathrm{g} / \mathrm{Nm}^{3}$. Konsentrasi gas $\mathrm{CO}$ yang kecil juga memiliki dampak yang buruk jika dihirup oleh manusia seperti gangguan pada sistem syaraf dan panca indera [1]. 


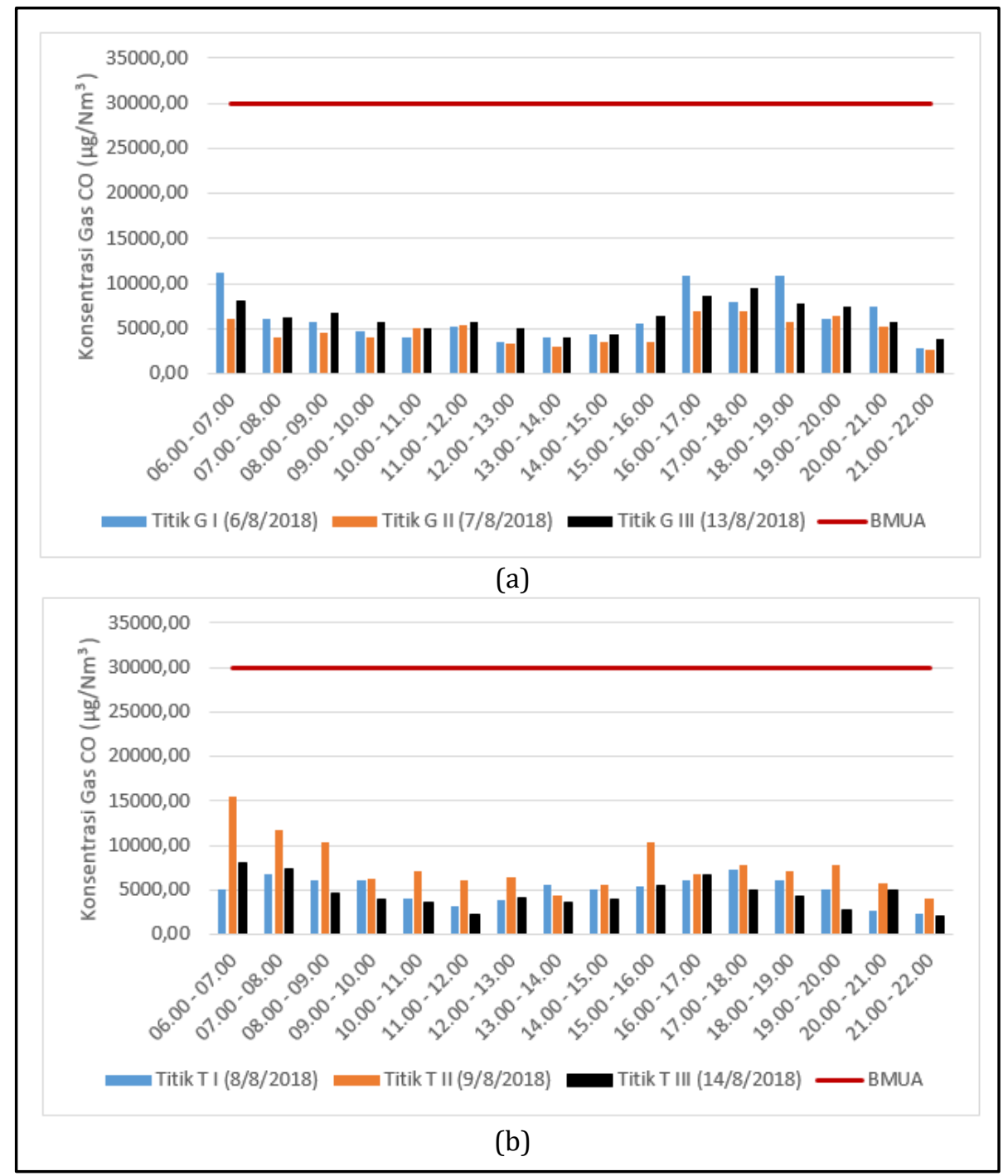

Gambar 3. Grafik konsentrasi gas CO di Jalan (a) Gajah Mada dan (b) Tanjungpura

\subsection{Suhu Udara}

Gambar 4(a) menunjukkan suhu udara di Jalan Gajah Mada. Suhu udara rata-rata pagi hari pukul $06.00-07.00$ WIB yaitu $27{ }^{\circ} \mathrm{C}$. Rata-rata suhu udara siang hari pukul 11.00 - 14.00 WIB naik menjadi $36,5^{\circ} \mathrm{C}$. Hasil pengukuran sore hari pukul 15.00 - $18.00 \mathrm{WIB}$, rata-rata suhu udara sebesar $33,8^{\circ} \mathrm{C}$. Suhu udara rata-rata malam hari pukul $20.00-22.00$ WIB cenderung menurun kembali yaitu $28,4^{\circ} \mathrm{C}$.

Gambar 4(b) menunjukkan suhu udara di Jalan Tanjungpura. Suhu udara rata-rata pagi hari pukul $06.00-07.00$ WIB yaitu $26,5^{\circ} \mathrm{C}$. Ratarata suhu udara siang hari pukul $11.00-12.00$ WIB naik menjadi $36,5^{\circ} \mathrm{C}$. Hasil pengukuran sore hari pukul 15.00 - 18.00 WIB, rata-rata suhu udara sebesar $32,5{ }^{\circ} \mathrm{C}$. Suhu udara rata-rata malam hari pukul $20.00-22.00$ WIB menurun kembali menjadi $27,7^{\circ} \mathrm{C}$.

Suhu udara pada siang hari cenderung lebih tinggi dibandingkan pagi, sore, dan malam hari. Kondisi tersebut menunjukkan intensitas matahari yang jauh lebih tinggi terjadi pada siang hari sehingga menyebabkan peningkatan suhu udara [8]. Hal tersebut dipengaruhi oleh matahari sebagai sumber energi panas terbesar yang menyinari permukaan bumi. Suhu udara di permukaan bumi akan berubah-ubah dan terus mengalami fluktuasi. Beberapa faktor penyebab terjadinya fluktuasi suhu udara yaitu intensitas cahaya matahari, sudut datang sinar matahari, kondisi awan, kemiringan matahari, dan kondisi permukaan bumi [9]. 


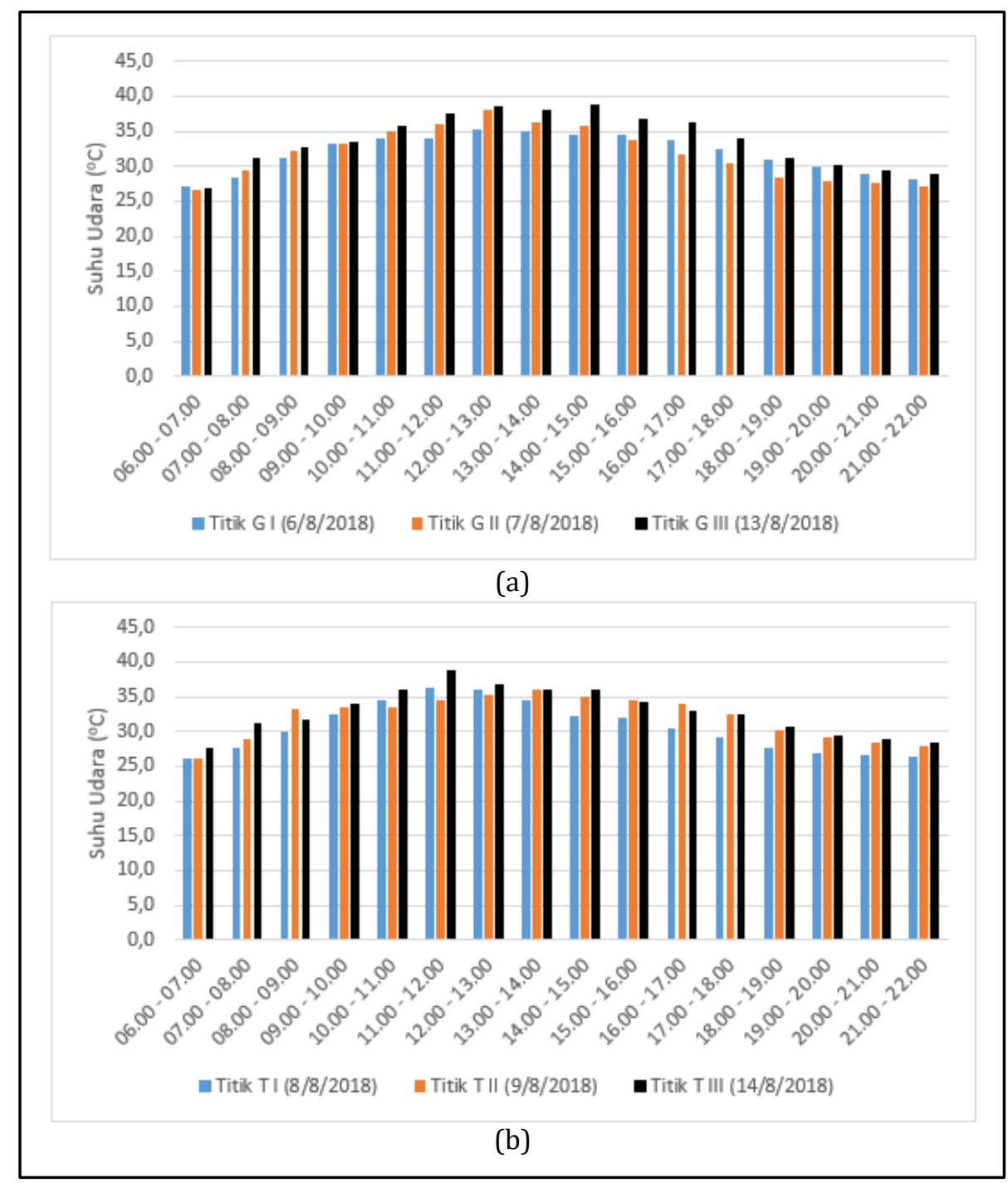

Gambar 4. Grafik suhu udara di Jalan (a) Gajah Mada dan (b) Tanjungpura

\subsection{Hubungan Suhu Udara Terhadap Gas CO}

Gambar 5 menunjukkan hubungan suhu udara terhadap konsentrasi gas CO di Jalan Gajah Mada dan Jalan Tanjungpura. Secara umum, naiknya suhu udara akan diikuti dengan turunnya konsentrasi gas CO dan sebaliknya. Suhu udara yang tinggi menyebabkan pemuaian molekul air di udara sehingga muatan air akan menurun dan menjadi renggang. Hal tersebut menyebabkan terjadinya penyebaran polutan sehingga konsentrasi gas pencemar menjadi rendah. Ketika suhu udara rendah kondisi udara menjadi stabil dan dapat menyebabkan polutan cenderung mengendap, sehingga konsentrasi bahan pencemar di udara makin tinggi [6].

Berdasarkan data yang diperoleh, konsentrasi gas CO tidak dipengaruhi secara signifikan oleh suhu udara. Konsentrasi gas CO cenderung meningkat ketika suhu udara rendah, namun konsentrasi bisa menurun meskipun suhu udara rendah. Pada malam hari, penurunan suhu udara tidak sepenuhnya diikuti oleh peningkatan konsentrasi gas CO. Hal tersebut disebabkan oleh faktor lain yaitu penurunan jumlah sumber pencemar, seperti kendaraan bermotor. Kadar gas CO yang berada di udara berkorelasi positif dengan kepadatan lalu lintas [10]. Pada kondisi normal ketika tidak ada faktor anthropogenik (aktivitas manusia), suhu udara menunjukkan hubungan yang cenderung konsisten berbanding lurus terhadap konsentrasi gas CO. Namun ketika terdapat faktor anthropogenik, maka hubungan antara suhu udara terhadap gas CO menjadi tidak konsisten. Ketidakkonsistenan tersebut diduga karena adanya pengaruh aktivitas manusia yang berananeka ragam seperti aktivitas transportasi, perdagangan, dan lain-lain [11]. Kondisi suhu udara pada malam hari cenderung menurun begitu pula dengan aktivitas manusia yang juga ikut berkurang. Hal tersebut yang menjadi penyebab hubungan antara suhu udara dan gas CO pada malam hari berbanding lurus dalam penelitian ini. 


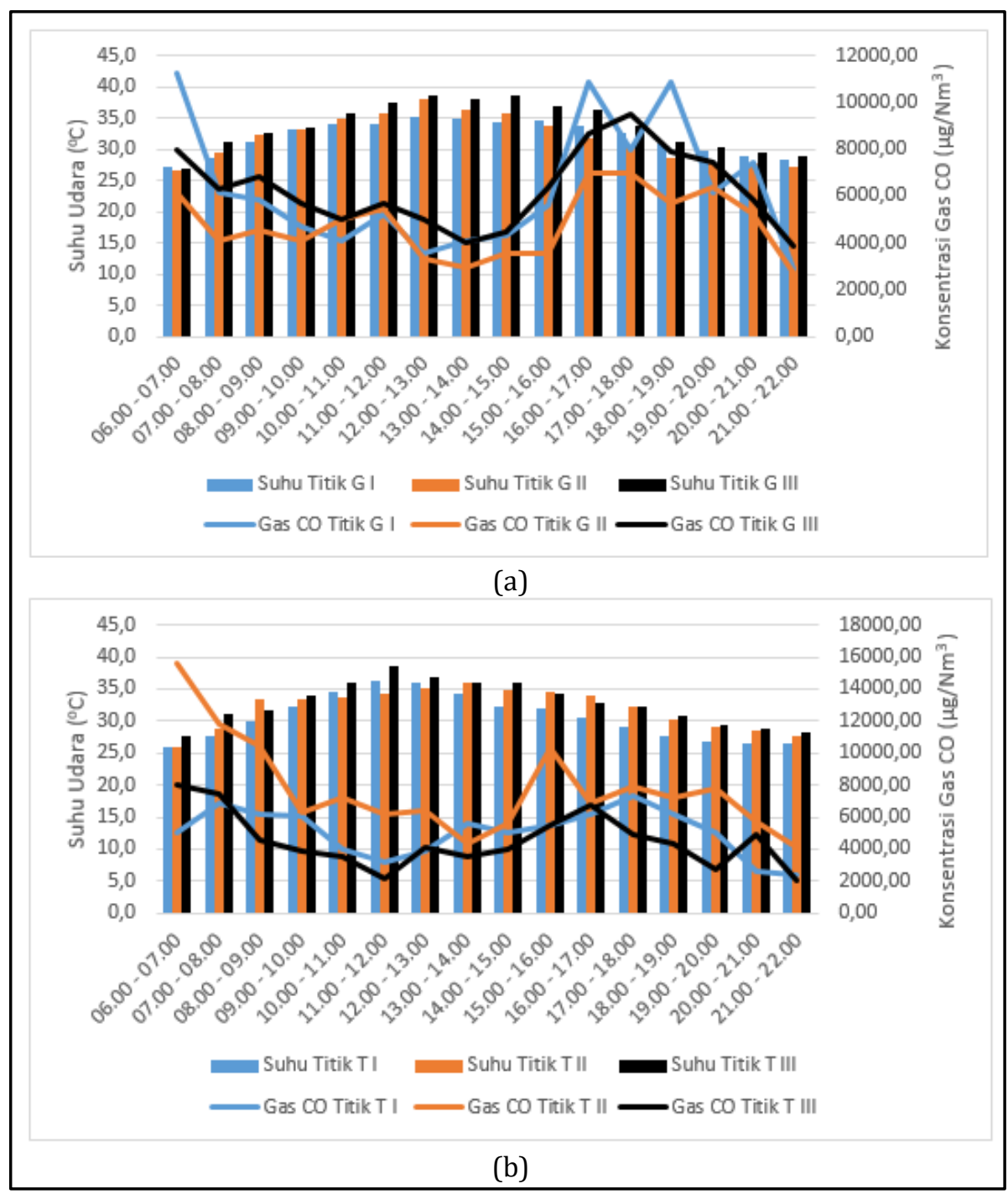

Gambar 5. Grafik hubungan suhu udara terhadap konsentrasi gas CO di Jalan (a) Gajah Mada dan (b) Tanjungpura

\section{Kesimpulan}

Kesimpulan dari penelitian ini yaitu kadar gas CO di Jalan Gajah Mada berkisar antara 2.746,69-11.215,66 $\mu \mathrm{g} / \mathrm{Nm}^{3}$ dan Jalan Tanjungpura berkisar 2.060,02-15.564,58 $\mu \mathrm{g} / \mathrm{Nm}^{3}$. Nilai tersebut tidak melebihi ambang batas baku mutu udara ambien (BMUA) yang ditetapkan oleh PERMENLH No. 12 Tahun 2010, yaitu $30.000 \mu \mathrm{g} / \mathrm{Nm}^{3}$.

Suhu udara yang tinggi menyebabkan konsentrasi gas CO cenderung menurun dan sebaliknya. Hal tersebut disebabkan pada suhu udara yang tinggi, udara lebih mudah memuai sehingga dispersi udara akan terjadi lebih cepat akibatnya konsentrasi gas pencemar menjadi rendah.

\section{Daftar Pustaka}

[1] Wardhana, A. W., Dampak Pencemaran Lingkungan, III ed, Yogyakarta: ANDI, 2004.
[2] Maryanto, D., Mulasari, A. S., dan Suryani, D., Penurunan Kadar Emisi Gas Buang Karbon Monoksida (CO) dengan Penambahan Arang Aktif pada Kendaraan Bermotor di Yogyakarta, Jurnal KESMAS, 3(3), 162-232, 2009.

[3] Aprianto, Y., Nurhasanah., dan Sanubary, I., Prediksi Kadar Particulate Matter (PM10) untuk Pemantauan Kualitas Udara Menggunakan Jaringan Syaraf Tiruan Studi Kasus Kota Pontianak, POSITRON, 8(1), 1520, 2018.

[4] Gultom, N., Sudarno, S., dan Handayani, S. D., Pengaruh Jumlah Kendaraan dan Faktor Meteorologi Terhadap Konsentrasi Karbon Monoksida (CO) di Jalan Ahmad Yani Kawasan Simpang Lima Kota Semarang. Jurnal Teknik Lingkungan, 3(1), 1-12, 2014.

[5] Manulang, S. M., Sudarno, S., dan Handayani, S. D., Pengaruh Jumlah Kendaraan dan 
Faktor Meteorologi Terhadap Konsentrasi Karbon Monoksida (CO) di Jalan Gajahmada Kawasan Simpang Lima Kota Semarang, Jurnal Teknik Lingkungan, 3(1), 1-12, 2014.

[6] Ginting, I. A. P., Analisis Pengaruh Jumlah Kendaraan Bermotor dan Faktor Meteorologi (Suhu, Kecepatan Angin dan Kelembaban) Terhadap Konsentrasi Karbon Monoksida (CO) di Udara Ambien Roadside (Studi Kasus Pintu Tol Amplas dan Pintu Tol Tawang Morawa), Fakultas Teknik., Universitas Sumatera Utara., Medan, 2017.

[7] Kementerian Lingkungan Hidup, Peraturan Menteri Negara Lingkungan Hidup Nomor 12 Tahun 2010 tentang Pelaksanaan Pengendalian Pencemaran Udara di Daerah, Jakarta: Kementerian Lingkungan Hidup, 2010.

[8] Winardi, Pengaruh Suhu dan Kelembaban Terhadap Konsentrasi $\mathrm{Pb}$ di Udara Kota Pontianak, Jurnal Penelitian dan Pengembangan Borneo Akcaya, 1(1), 16-22, 2014.

[9] Fadholi, A., Pemanfaatan Temperatur Udara dan Kelembapan Udara dalam Persamaan Regresi untuk Simulasi Prediksi Total Hujan Bulanan di Pangkalpinang, Jurnal CAUCHY, 3(1), 1-9, 2013.

[10] Akhadi, M., Ekologi Energi, Mengenali Dampak Lingkungan dalam Pemanfaatan Sumber-Sumber Energi, I ed, Yogyakarta: Graha Ilmu, 2009.

[11] Aprilina, K., Badriah, I. U., dan Aldrian, E., Hubunagn Antara Konsentrasi Karbon Monoksida (CO) Dan Suhu Udara Terhadap Intervensi Anthropogenik (Studi Kasus Nyepi Tahun 2015 Di Provinsi Bali), Jurnal Meteorologi dan Geofisika, 17(I), 53-60, 2016. 